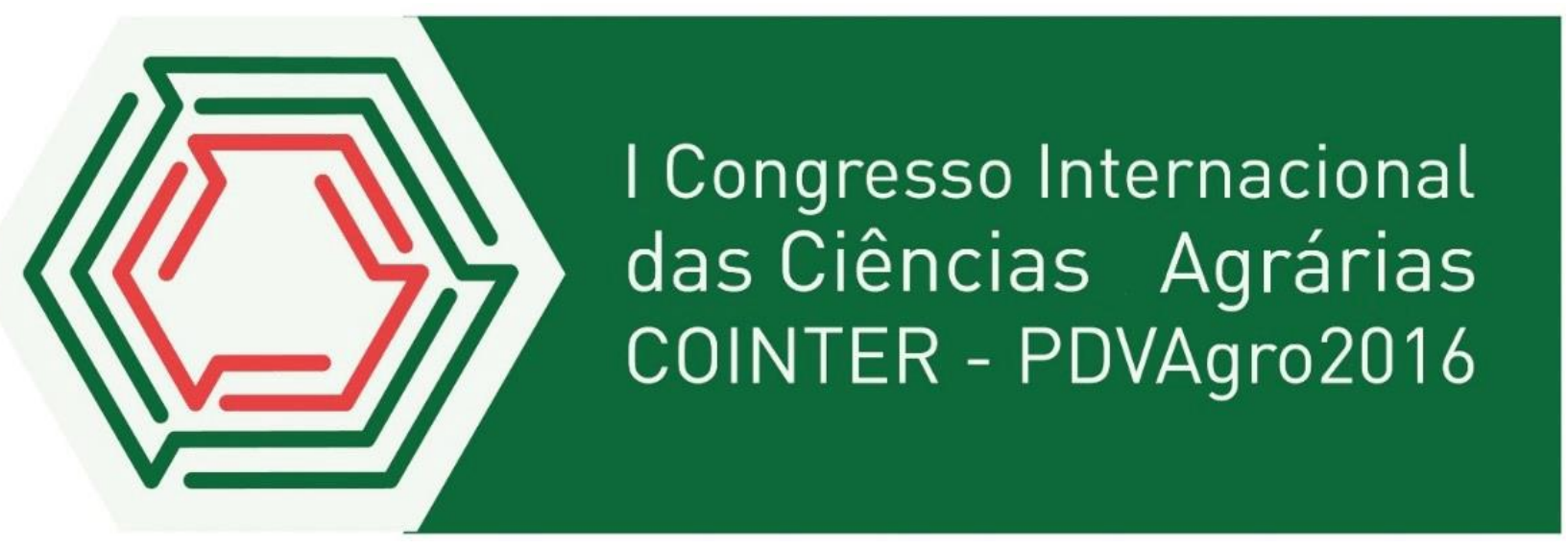

\title{
MAPEAMENTO DA TEMPERATURA DO SOLO EM DIFERENTES ÁREAS DA CAATINGA PELO USO DO GEOPROCESSAMENTO
}

\author{
Apresentação: Pôster
}

\begin{abstract}
Paulo César Alves do Ó ${ }^{1}$; Lucas Jónatan Rodrigues da Silva ${ }^{2}$; Erickson Melo de Albuquerque $^{3}$; Cícera Tiburtino da Silva ${ }^{4}$; Ane Cristine Forte da Silva ${ }^{5}$.
\end{abstract}

\section{Introdução}

A temperatura do solo é um fator variável no tempo e no espaço assumindo grande importância nos processos físicos, químico e biológico, influenciando no crescimento e desenvolvimento vegetal. (HILLEL, 1998; MOTA, 1989). A mesma tem influência no crescimento das plantas, com seu efeito na atividade fisiológica e indiretamente na disponibilidade de nutrientes do solo (PAUL et al., 2003).

As flutuações diárias e anuais da temperatura do solo influenciam nos processos de nutrição, nas taxas de decomposição e de mineração da matéria orgânica e da liberação de $\mathrm{CO}_{2}$ no solo, além de ser um dos principais fatores de influência da respiração do solo (GRAHAM et al., 2010).

Segundo Castro (1989), a cobertura do solo reduz sua temperatura durante as horas mais quentes do dia. Bragagnolo e Mielniczuk (1990) afirmam que a cobertura do solo, além de reduzir as perdas de água por evaporação, mantém a temperatura do solo em níveis mais baixos. Altas temperaturas têm efeitos negativos sobre plântulas e raízes e na atividade microbiana, simultaneamente, provocam ainda maiores perdas por evaporação, principalmente no preparo convencional, pois a secagem da camada superficial do solo é mais rápida, influenciando negativamente esses fatores (DERPSCH et al., 1991).

\footnotetext{
${ }^{1}$ Tecnologia em Gestão Ambiental - "Bolsista do PIBICT - IFPB”, Instituto Federal da Paraíba, pcalvesdoo@gmail.com

${ }^{2}$ Tecnologia em Gestão Ambiental - "Bolsista do PIBICT - IFPB", Instituto Federal da Paraíba, lucasrodriguesejc@gmail.com

${ }_{3}^{3}$ Mestre em Meteorologia, Professor do Instituto Federal da Paraíba, erickson.melo@gmail.com

${ }^{4}$ Gestora Ambiental, Instituto Federal da Paraíba, ciceraod@gmail.com

${ }^{5}$ Doutorando em Ciências Florestais, Universidade Federal Rural de Pernambuco, Professora do Instituto Federal da Paraíba, ane.silva@ifpb.edu.br
} 
Diante do exposto, o objetivo deste estudo foi determinar as variações na temperatura do solo em três diferentes áreas de sucessão ecológica sob vegetação Caatinga através de mapeamento de interpolação espacial e geoprocessamento.

\section{Fundamentação Teórica}

A cobertura vegetal é uma das principais formas para criar um ambiente favorável às plantas, aumentando a cobertura do solo e assim reduzindo sua temperatura durante as horas mais quentes do dia (CASTRO, 1989). Esse autor afirma ainda que o excessivo aquecimento do solo compromete a absorção de nutrientes pelas plantas.

A temperatura é influenciada por uma série de fatores, como as condições meteorológicas, topografia local, tipo de solo, teor de água, textura, área de superfície coberta e copa das plantas. Desta forma, o conhecimento do material vegetal depositado sobre o solo, resultante dos componentes envelhecidos da parte aérea das plantas que caem no solo e que compreende as folhas, caules, flores e frutos, reveste-se de grande importância no estudo de ecossistemas florestais (TOLEDO et al., 2002).

Devido a isso, o conhecimento da dinâmica da temperatura do solo é fundamental para o entendimento do meio ambiente e seus ecossistemas, pois sua variação interfere na germinação de plantas, no crescimento radicular, na absorção de água e nutrientes pelas plantas e na atividade microbiana do solo (HILLEL, 1998).

\section{Metodologia}

O estudo foi desenvolvido em três áreas experimentais situadas no interior do Instituto de Educação, Ciência e Tecnologia da Paraíba (IFPB), localizada no município de Princesa Isabel PB. O clima local, segundo a classificação de Köppen, é do tipo Aw', Tropical Quente e Úmido com chuvas de verão-outono. A topografia do terreno apresenta-se bastante ondulada e o solo é classificado como Argissolo vermelho amarelo. Os sítios experimentais foram fragmentos de Caatinga definidos conforme o estágio de sucessão ecológica no local, a saber: estágio secundário de sucessão (ES), estágio inicial de sucessão (EI) e área degradada (AD).

A temperatura do solo foi medida entre os meses de maio a agosto de 2016 entre 09:00 e 11:00 horas com auxilio de termômetro infravermelho Benetech $\left(-50{ }^{\circ} \mathrm{C} \sim 420{ }^{\circ} \mathrm{C}\right)$. Coletou-se 30 pontos de temperatura em cada área por mês aleatoriamente na superfície do terreno. Para a elaboração dos mapas de temperaturas das áreas usou-se a interpolação espacial, e como ferramenta o programa Surfer 8.0, adotando suas nomenclaturas para os métodos de interpolação. O método 
utilizado foi a krigagem, utilizando a geoestatística para efetuar a interpolação, o que em muitos casos é uma grande vantagem sobre outros métodos. Geoestatística é uma ciência relativamente nova, derivada da estatística aplicada que trata de problemas referentes às variáveis regionalizadas (BICUDO; BICUDO, 2004).

\section{Resultados e Discussões}

As áreas de sucessão ecológica mostraram variação de temperaturas, sendo as maiores índice de temperatura na área degradada com mínima de $35,0{ }^{\circ} \mathrm{C}$ e máxima de $39,2{ }^{\circ} \mathrm{C}$, na área de estagio inicial a temperatura variou entre $31,4{ }^{\circ} \mathrm{C}$ a $35,8{ }^{\circ} \mathrm{C}$, já na área de estagio secundário a variação da temperatura apresentou os índices mais baixos com mínima de $26,3{ }^{\circ} \mathrm{C}$ e máxima de $29,3^{\circ} \mathrm{C}$ (figura 1 ).

Figura 1 - Mapeamento da temperatura do solo com uso do geoprocessamento em diferentes áreas da Caatinga: área degradada (a), estagio inicial (b) e estagio secundário.
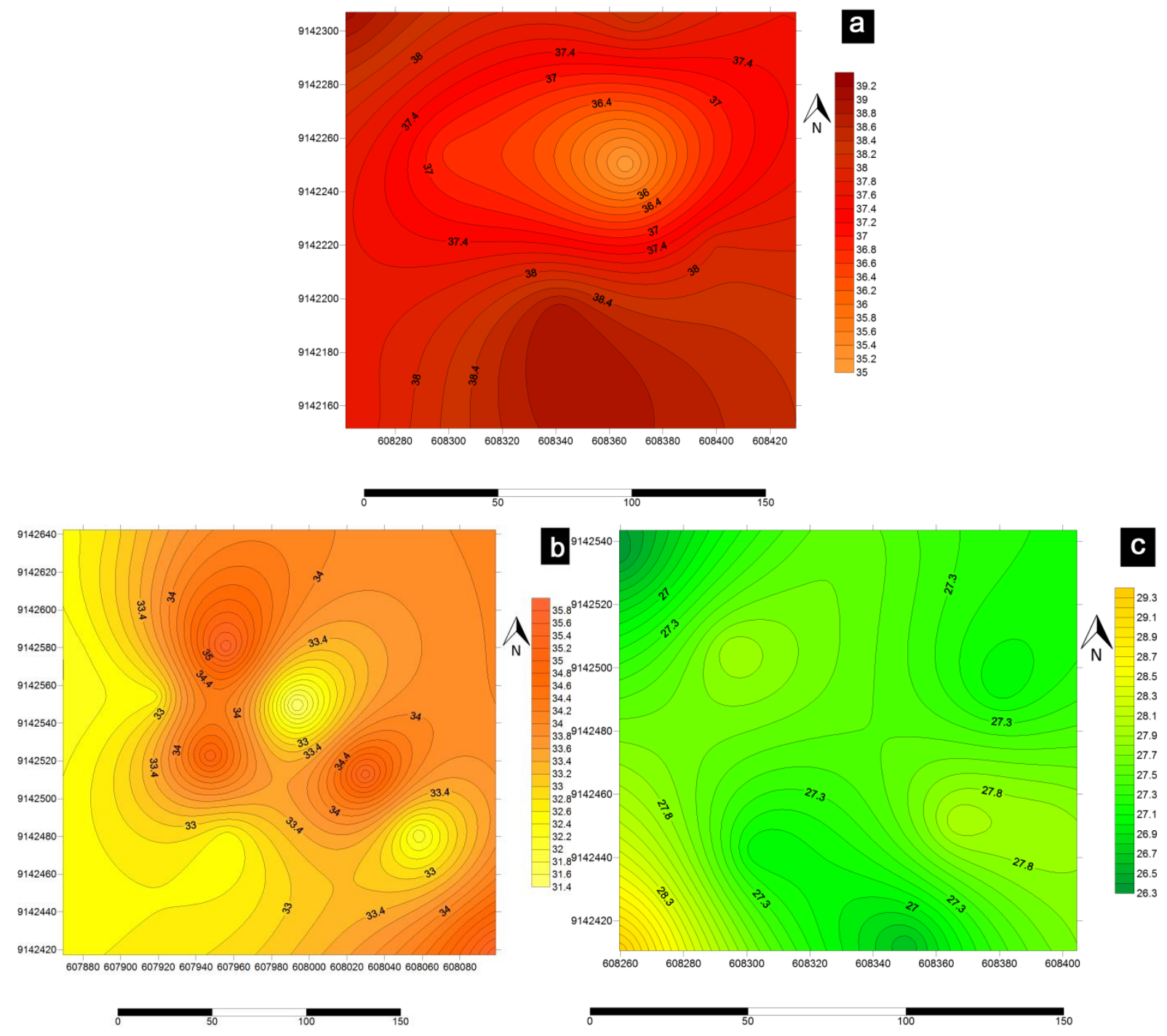
Fonte: Autores (2016)

A presença da maior temperatura na área degrada está relacionada a pouca quantidade e à baixa distribuição da cobertura vegetal nessa área. Os poucos resíduos vegetais sobre o solo, não consegue reduzir a temperatura e a amplitude térmica, devido à reflexão e à absorção de energia solar incidente, aumentando assim a perda de água por evaporação (WIERENGA et al., 1982). Pode também associar a elevada temperatura nessa área, devido o manejo inadequado. A retirada da vegetação arbórea para uso do solo com cultivos agrícolas anuais e pastagens em tempos passados, assim deixando o solo exposto, influencia diretamente para a elevação da temperatura no solo em maior.

$\mathrm{Na}$ área de estagio inicial, nota-se a temperatura intermediaria aos valores apresentados na $\mathrm{AD}$ e ES. Isso acontece, pois a vegetação da área apresenta um ambiente mais homogêneo com predomínio de espécies arbustivas e, poucos indivíduos arbóreos, porem em relação à $\mathrm{AD}$, nota-se uma diferença significativa na massa arbórea, assim a tendência é uma temperatura não tão elevada, porem com valores maiores que a áreas de ES.

A área de sucessão ecológica secundaria apresentou os menores índices de temperaturas, isso é associado à massa arbórea na área, já que a mesma já esta aproximadamente 30 anos sem interferência antrópica, além de ser composta por um ambiente heterogêneo em termos de flora, com espécies arbóreas nativas dominando a estrutura da paisagem. A vegetação encontra-se em um nível mais avançado de formação, com espécies de porte mais elevado. Essas características fazem com que a temperatura no solo nesse ambiente seja mais baixa, com menor reflexão dos raios solar.

Segundo Bragagnolo e Mielniczuk (1990), o efeito das coberturas vegetais sobre a temperatura do solo depende da quantidade, qualidade e distribuição dos resíduos sob o solo, fato que concorda com as maiores reduções em temperatura do solo encontradas no campo com quantidade maior de plantas de cobertura.

O efeito das coberturas vegetais, comparativamente com o solo descoberto, torna-se mais evidente, o que é demonstrado, principalmente, nas horas mais quentes do dia. As temperaturas mais elevadas e com maiores amplitudes de variação em solo descoberto são demonstradas em diversos estudos, evidenciando a importância da cobertura vegetal como agente amenizador da temperatura do solo (BRAGAGNOLO; MIELNICZUK, 1990). 


\section{Conclusões}

A temperatura do solo mostrou diferença entre as três áreas de sucessão ecológicas estudadas, com temperaturas mais elevadas na área degradada e menor temperatura na área de sucessão de estagio secundário.

A cobertura vegetal influencia diretamente na temperatura do solo, quanto menor a massa arbórea, mais alta se apresenta os valores, isso mostra a importância da cobertura da vegetação nas áreas estudadas, principalmente em áreas degradadas.

\section{Agradecimentos}

Este trabalho foi realizado com apoio do Programa Institucional de Bolsas de Iniciação Cientifica e Tecnologia - IFPB

\section{Referências}

BICUDO, C. E. M.; BICUDO, D. C. Amostragem em limnologia. RiMa, São Carlos, p.371. 2004

BRAGAGNOLO, N.; MIELNICZUK, J. Cobertura do solo por palha de trigo e seu relacionamento com a temperatura e umidade do solo. Revista Brasileira de Ciência do Solo, Viçosa, v. 14, p. 8184, 1990.

CASTRO, O.M. Preparo do solo para a cultura do milho. Campinas, Fundação Cargill, p.41, 1989.

DERPSCH, R.; et al. Controle da erosão no Paraná, Brasil: Sistemas de cobertura do solo, plantio direto e preparo conservacionista do solo. Eschborn, GTZ, p.272.1991.

GRAHAM, E. A. et al. Forest understory soil temperatures and heat flux calculated using a Fourier model and scaled using a digital camera. Agricultural and Forest Meteorology, v.150, p.640-649, 2010.

HILLEL, D. Environmental Soil Physics. Academic Press, p.770, 1998.

MOTA, F.S. Meteorologia agrícola. São Paulo, Nobel, p.201. 1989.

PAUL, K. I. et al. Soil temperature under forest: a simple model for predicting soil temperature under a range of forest types. Agricultural and Forest Meteorology, v.121, p.167-182, 2003.

TOLEDO, L. et al. Produção de serapilheira e transferência de nutrientes em florestas secundárias localizadas na região de pinheiral, RJ. Revista Ciência Florestal, v.12, p.9-16, 2002.

WIERENGA, P.J et al. Tillage effects on soil temperature and thermal conductivity. In: ANNUAL MEETING SOIL SOCIETY OF AGRONOMY, 30., Detroit, 1980. Proceeding. Detroit, Soil Science Society America, p.69-90. 1982. 